\title{
El poblado de Alarcos (Ciudad Real) en los inicios del I milenio a.C.: estructuras y materiales cerámicos*
}

\author{
The Alarcos settlement (Ciudad Real) in the early first millennium BC: \\ Structures and ceramics
}

\section{M. ${ }^{a}$ del Rosario García Huerta ${ }^{\mathrm{a}}$ y F. Javier Morales Hervás ${ }^{\mathrm{a}}$}

\section{RESUMEN}

Hasta finales del siglo XX la etapa protohistórica correspondiente al Bronce Final- Hierro I en el área sudoccidental de la Meseta no contaba con una documentación arqueológica suficientemente amplia para proceder a su caracterización. En los últimos años los trabajos desarrollados en poblados como Alarcos han logrado obtener una interesante información sobre estructuras de hábitat que han permitido contextualizar y fechar un amplio y variado elenco de cerámicas pintadas postcocción, entre otros materiales arqueológicos, que solo se conocían por prospección superficial. Destaca una vajilla cuidada decorada, pensada para un uso selecto que reproduce modas y costumbres de clara inspiración tartésica como las cerámicas de tipo Carambolo y de retícula bruñida, cuya presencia no sería resultado de una posible colonización tartésica sino el fruto de intercambios comerciales. Gracias a la investigación en curso se empiezan a detallar las características del nuevo patrón de poblamiento que empieza a gestarse en la transición del II al I milenio a.C. en el valle medio del Guadiana, cuyo dinamismo y relaciones comerciales con el Bajo Guadalquivir ponen de manifiesto los materiales cerámicos de este estudio. to be properly characterized until the final years of the 20th century. However, recent work at settlements such as Alarcos (Ciudad Real) has obtained valuable information about the habitat structures and a large amount of well contextualized archaeological material (mainly pottery painted after firing). These are carefully-made tablewares whose decoration indicates a selective adoption of fashions and customs of Tartessian inspiration (e.g., Carambolo type and burnished-lattice ceramics) as consequence of commercial exchanges. This new data is helping us achieve a better understanding of the new settlement patterns that started to appear at that time in the middle valley of the Guadiana river and shows the dynamism of the communities located there.

Palabras clave: Bronce Final; Hierro I; Período Preibérico; Alarcos; Arqueometría cerámica; Estructuras de habitación; Oretania.

Key words: Final Bronze; Early Iron Age; Pre-iberian period; Alarcos; Ceramic archaeometry; Habitat structures; Oretania.

\section{INTRODUCCIÓN}

El oppidum de Alarcos se ubica sobre un gran cerro de unas 33 has, dotado con unas buenas defensas naturales; su cota más alta se eleva unos

The final Bronze Age and Early Iron Age of the south-western Meseta were insufficiently documented

* Proyectos "Intervención arqueológica en el Parque Arqueológico de Alarcos (Ciudad Real). Tipo: Artículo 83- Contrato de I+D. Referencia UCTR 130356", ejecutado en 2013, e "Investigaciones Arqueológicas en la necrópolis de Alarcos y el Sector II del yacimiento de Alarcos (Ciudad Real).Tipo: DGC/SPA SBPLY/14180601/000023” llevado a cabo en 2014. La Consejería de Educación y Cultura de la Junta de Comunidades de Castilla-La Mancha financió ambos.

a Dpto. de Historia, Universidad de Castilla-La Mancha. Avda. Camilo José Cela s/n. 13071 Ciudad Real. Correos e.: rosario. garcia@uclm.es http://orcid.org/0000-0003-3201-9032; Fco.morales@uclm.es http://orcid.org/0000-0002-2490-6515.

Recibido 30-III-2016; aceptado 15-VII-2016. 
$100 \mathrm{~m}$ sobre el valle medio del Guadiana (Fig. 1). Situado a escasos km de Ciudad Real, constituye uno de los yacimientos de la Meseta meridional en proceso de investigación cuya ocupación es más completa: desde finales de la Edad del Bronce hasta época medieval. Después de unos veinticinco años de excavaciones arqueológicas, las etapas ibérica y medieval eran las mejor conocidas. De la primera ocupación del cerro sólo se tenían noticias a partir de una serie de materiales cerámicos recuperados fuera de contexto en distintas zonas del yacimiento, cuyo estudio y publicación (García Huerta y Rodríguez 2000) se ha actualizado recientemente (Fernández Rodríguez 2012).

A efectos metodológicos el yacimiento se dividió en los sectores I, II, III, IV, IV-E y Alcazaba. El presente trabajo está basado en las investigaciones arqueológicas llevadas a cabo, desde 1997, en el sector III situado en la ladera sureste del cerro que documentaron una ocupación medieval sobre otra ibérica constituida por un gran edificio de almacenamiento y, bajo estos niveles, evidencias de un poblamiento anterior. Hasta ahora sólo conocíamos esta primera ocupación por materiales cerámicos descontextualizados, debido a la importante afección provocada por la ejecución de notables estructuras tanto en época ibérica como medieval. Sin embargo en las últimas campañas arqueológicas hemos podido documentarlos, asociados a estructuras de habitación.

La primera ocupación del cerro se produce a finales de la Edad del Bronce, continúa en época ibérica y alcanza su momento de mayor esplendor desde finales del siglo V al III a.C. (Fernández Rodríguez y García Huerta 1998: 53). Las grandes dimensiones de este oppidum (16 a 20 has) en época ibérica, sus estructuras y los materiales arqueológicos encontrados revelan la importancia que alcanzó dentro de la Oretania. A este período se adscribe un edificio de grandes dimensiones, dedicado al almacenamiento y a la transformación de alimentos (García Huerta y Morales 2009). Las fosas de cimentación excavadas para su construcción, alteraron en gran parte los niveles de ocupación previos, uno ibérico y otro más antiguo correspondiente al Bronce Final-Hierro I. Este trabajo estudiará este nivel antiguo a partir de las estructuras de habitación y los materiales arqueológicos localizados tanto bajo el almacén ibérico, como en otras áreas sin construcciones ibéricas encima lo que ha favorecido su conservación.
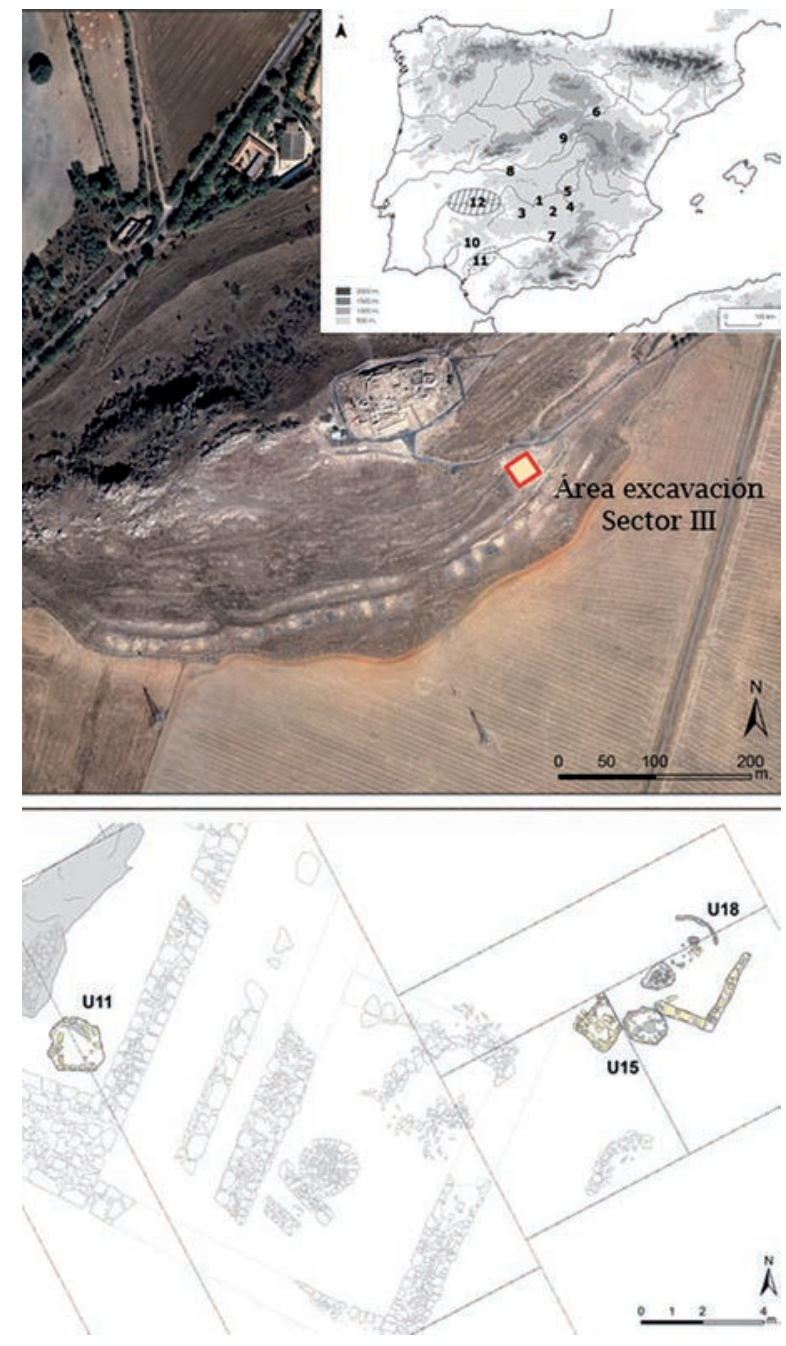

Fig. 1. Localización de los poblados citados en el texto en el mapa de la península ibérica: 1. Alarcos (Ciudad Real), 2. Cerro de las Cabezas (Valdepeñas), 3. La Bienvenida (Almodóvar del Campo), 4. Peñarroya (Argamasilla de Alba), 5. Cerro de las Nieves (Pedro Muñoz, Ciudad Real); 6. Ogmico (Monreal de Ariza, Zaragoza); 7. Cástulo (Linares, Jaén); 8. Casa del Carpio (Belvis de la Jara, Toledo); 9. Alovera (Guadalajara); El Trastejón (Zufre, Huelva); 11. El Carambolo (Sevilla). Zona rayada: Extremadura; zona punteada: Bajo Guadalquivir. La zona excavada, en la vista general desde el aire del cerro de Alarcos, muestra las viviendas y hogares del I milenio cal $\mathrm{AC}$ entre las construcciones del periodo ibérico (Centro Nacional de Información Geográfica, 2013).

Los estudios sobre el periodo del Bronce Final y los inicios del Hierro en el alto y medio Guadiana son relativamente recientes por falta de información arqueológica. La interesante síntesis 
realizada por Pereira (1994: 37-85) de esta transición en la Meseta sur apenas menciona la zona, revelando la ausencia de datos en ese momento al estar en sus inicios las excavaciones arqueológicas en Alarcos, La Bienvenida y el cerro de Las Cabezas, los tres grandes yacimientos de la provincia de Ciudad Real. El desarrollo de estas investigaciones $\mathrm{y}$, por tanto el incremento de la información disponible, permitió a Zarzalejos y López Precioso (2005: 815) elaborar un trabajo sobre este período. Sitúan el inicio del poblamiento en La Bienvenida entre fines del siglo VIII y principios del VII a.C., en el cerro de las Cabezas entre los siglos VIII y VI a.C. (Pérez y Vélez 1996: 17-18) y en el poblado de Alarcos entre los siglos VIII y VII a.C. (Fernández Rodríguez 2000: 129), es decir, en la transición entre el Bronce Final y el Hierro I, que denominan "orientalizante". Plantean que desde su inicio "quedan imbuidos en una dinámica cultural que les vincula con los ambientes tartésicos orientalizantes, configurando un espacio más a incluir dentro de la llamada periferia tartésica" (Zarzalejos y López 2005: 836).

Entre las aportaciones realizadas por los investigadores en los principales oppida del alto Guadiana, destaca nuestro estudio sobre el nivel más antiguo de ocupación de Alarcos (García Huerta y Fernández Rodríguez 2000). En el se presentaban exclusivamente cerámicas, en gran parte descontextualizadas por las construcciones ibéricas y/o medievales, que fechamos en la transición entre el Bronce Final-Hierro I. Pereira (2007) reflejó este y otros trabajos en su nueva visión de conjunto, donde uno de los ejes de articulación del desarrollo de la Meseta sur, en este período, eran los territorios occidentales de las actuales provincias de Toledo y Ciudad Real. Allí reconoce características de la fase orientalizante en el proceso de transición a la Edad del Hierro en asentamientos de la importancia de Alarcos, La Bienvenida y el cerro de las Cabezas (Pereira 2007: 155).

Posteriormente uno de nosotros (Morales 2010) estudió el poblamiento de época ibérica en Ciudad Real y puso de relieve, al analizar el sustrato indígena, que las comarcas de la provincia, salvo la montañosa del noroeste, contaban con evidencias arqueológicas adscribibles al periodo del Bronce Final-Hierro I. Dos nuevas aportaciones sobre el tema se presentaron en la reunión científica sobre el río Guadiana en el Bronce Final, celebrada en Mérida y Badajoz, en 2008. Fernández Rodríguez (2012) analiza diversos conjuntos cerámicos a mano del sector IV de Alarcos. Las fechas de radiocarbono incorporadas confirman un asentamiento humano en el poblado, al menos, entre finales del siglo IX a.C. y comienzos del siglo VII a.C. A su vez, Zarzalejos, Esteban y Hevia (2012), en su síntesis del alto Guadiana durante el Bronce Final, recalcan la presencia de materiales de esta etapa en las comarcas de la Mancha, Campo de Montiel, Campo de Calatrava y Valle de Alcudia de la provincia de Ciudad Real y presentan como novedad dos nuevas estelas encontradas en el entorno de $\mathrm{La}$ Bienvenida.

\section{DESCRIPCIÓN DE LOS ELEMENTOS CONSTRUCTIVOS}

A partir de los trabajos de excavación realizados entre 2004 y 2006 se han podido identificar cuatro hogares, un poste de cabaña y dos cabañas o viviendas (Fig. 1) correspondientes al Bronce Final-Hierro I.

\subsection{Hogar (Cata U11)}

En el sector norte del almacén se llegó a la base de su cimentación, unas arcillas rojizas típicas del período ibérico del cerro, con cerámicas ibéricas y otras a mano, así como restos de fauna. Al profundizar se alcanzó un nivel solo con cerámica a mano con el que se asociaba un hogar circular de 1,2 $\mathrm{m}$ de diámetro, formado por una capa de arcilla quemada hundida y delimitado por piedras pequeñas. Al levantar ésta salió otra capa de adobe quemado con fragmentos de cerámica también a mano lisa y más piedras, que servirían de base a la placa de hogar. La potencia total del hogar son $26 \mathrm{~cm}$ (Fig. 2).

El nivel en el que se sitúa este hogar precede la construcción del almacén ibérico, ya que la zanja de construcción de uno de sus muros, rellena de piedras, rompe el nivel antiguo, pero deja intacto el hogar, que es la única estructura de este período conservada en esta zona. Entre

Trab. Prehist., 74, N. ${ }^{\circ}$ 1, enero-junio 2017, pp. 108-126, ISSN: 0082-5638

doi: $10.3989 /$ tp. 2017.12186 


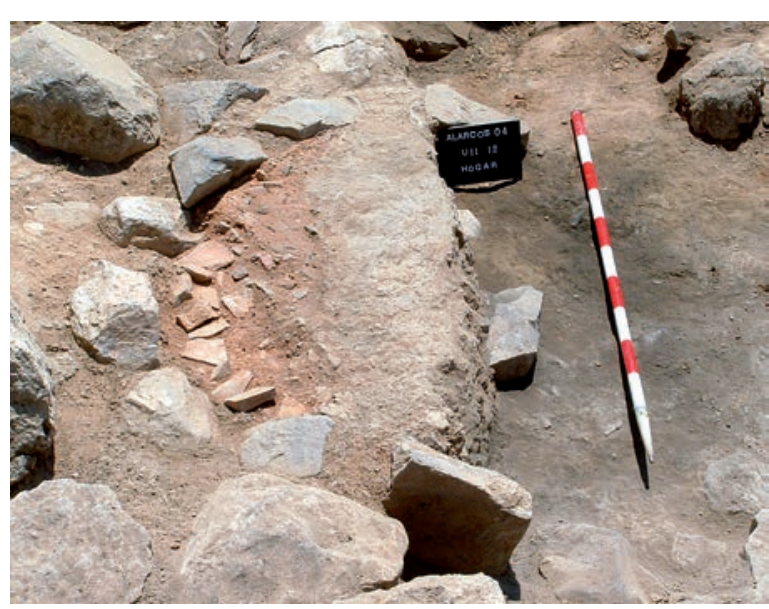

Fig. 2. Hogar de la Cata 11 del sector III de Alarcos, perteneciente a una vivienda de la ocupación del I milenio cal AC.

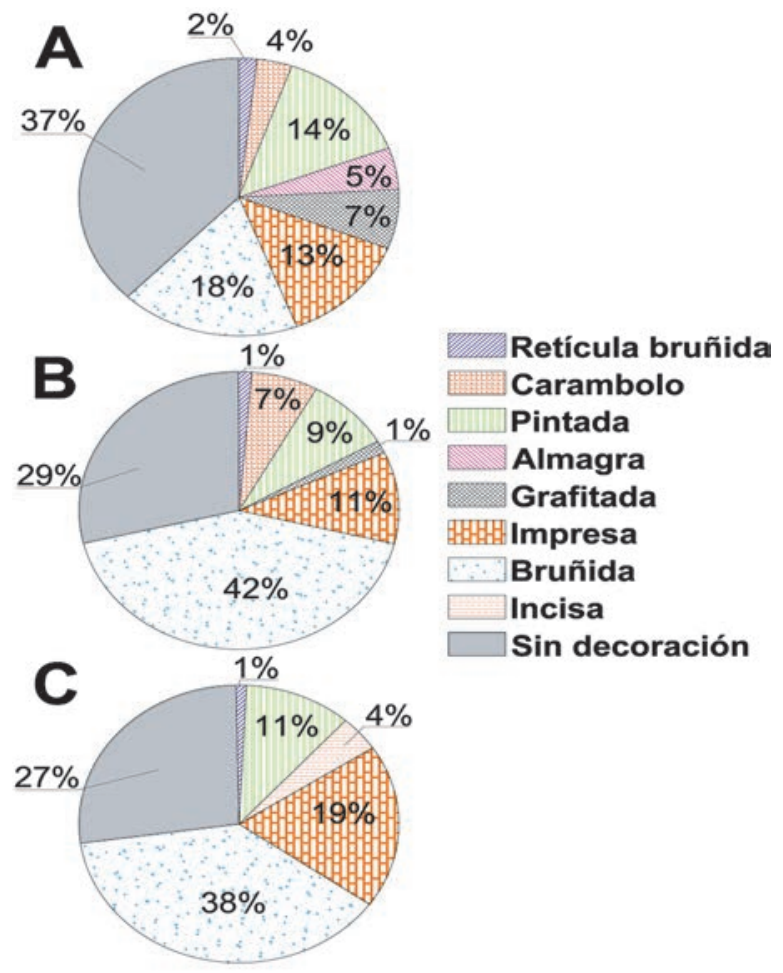

Fig. 3. Porcentaje de representación de los tipos cerámicos decorados y lisos del I milenio cal AC en las Catas 11 (A, total 109 frag.), 15 (B, total 53 frag.) y 18 (C, total 75 frag.) del sector III de Alarcos. las cerámicas destacan las pintadas postcocción monocromas y bícromas, las de tipo Carambolo, las bruñidas y las de superficies alisadas o toscas (Fig. 3A).

En este mismo nivel, pero en una zona más alejada del hogar, algo más alterada por la construcción del almacén ibérico, se documentaron además fragmentos de cerámicas de retícula bruñida, grafitadas, almagras e impresas, así como el único recipiente pintado postcocción prácticamente completo que hemos hallado (Fig. 4). La pasta y superficies son de color negro. Tiene forma globular con un pequeño cuello acabado en un borde redondeado ligeramente saliente. Una pintura bícroma, rojo y amarillo, lo cubre prácticamente por completo. La decoración es un friso con motivos geométricos consistente en rectángulos delineados en amarillo con rectángulos interiores formados por líneas rojas y en la parte central un rectángulo amarillo con una especie de aspa central. El friso está enmarcado en la parte inferior y superior por una banda horizontal formada por una banda ondulada amarilla entre tres pares de líneas rojas. En el cuello hay una banda amarilla y al interior del borde una línea roja. Las medidas son: altura $165 \mathrm{~mm}$, diámetro máximo $240 \mathrm{~mm}$, diámetro de la boca $140 \mathrm{~mm}$ y grosor $5 \mathrm{~mm}$. Las fechas C14 de este nivel proceden de la zona más alejada del hogar: $2410 \pm 40 \mathrm{BP}$ y $2390 \pm 40$ BP (Tab. 1).

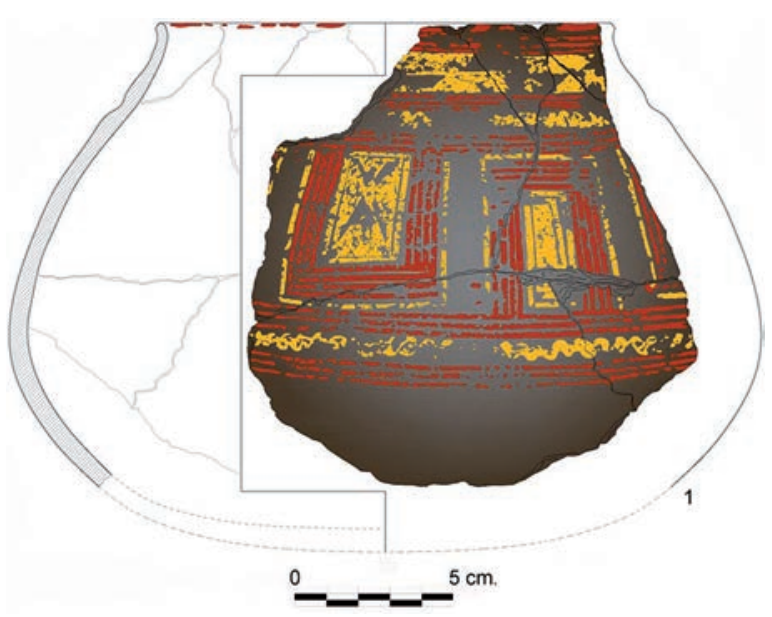

Fig. 4. Recipiente pintado asociado al hogar 1, Cata U-11, sector III de Alarcos. En color en la versión electrónica. 


\begin{tabular}{|c|c|c|c|c|c|c|}
\hline Cuadrícula/Nivel & Muestra & Referencia & Fecha BP & Ratio & Cal BC 1 sigma & Cal BC 2 sigma \\
\hline AL08-U15-5 & Carbón & Beta-250440 & $2470 \pm 40 \mathrm{BP}$ & -23.9 & $760-530 \mathrm{AC}$ & $780-410 \mathrm{AC}$ \\
\hline AL08-U15-4 & Carbón & Beta-250439 & $2760 \pm 40 \mathrm{BP}$ & -22.9 & $1000-900 \mathrm{AC}$ & $1020-840 \mathrm{AC}$ \\
\hline AL08-U15-3 & Carbón & Beta-250438 & $2550 \pm 40 \mathrm{BP}$ & -24.7 & $790-760 \mathrm{AC}$ & $800-730 \mathrm{AC}$ \\
\hline AL10-U11-MS-4 & Carbón & Beta-285377 & $2410 \pm 40 \mathrm{BP}$ & -25.1 & $530-400 \mathrm{AC}$ & $750-690 \mathrm{AC}$ \\
\hline AL10-U15-9 & Carbón & Beta-285378 & $2500 \pm 40 \mathrm{BP}$ & -25.9 & $760-530 \mathrm{AC}$ & $780-410 \mathrm{AC}$ \\
\hline AL10-U18-2 & Carbón & Beta-285379 & $2590 \pm 40 \mathrm{BP}$ & -24.8 & $800-780 \mathrm{AC}$ & $810-760 \mathrm{AC}$ \\
\hline AL10-U18-5-1 & Carbón & Beta-285380 & $2600 \pm 40 \mathrm{BP}$ & -23 & $810-790 \mathrm{AC}$ & $840-780 \mathrm{AC}$ \\
\hline AL11-U11-MS-7 & Carbón & Beta-304376 & $2390 \pm 40 \mathrm{BP}$ & -23.6 & $530-400 \mathrm{AC}$ & $750-690 \mathrm{AC}$ \\
\hline
\end{tabular}

Tab. 1. Cuadro de fechas de C14 del sector III de Alarcos (calibradas según Talma y Vogel 1993; Reimer et al. 2004).

\subsection{Hogar (Cata U15)}

La Cata U15 está fuera del espacio ocupado por el almacén ibérico, en la ladera del cerro. En su esquina noreste, bajo un potente paquete de las arcillas rojas características de la ocupación ibérica, apareció una estructura de forma rectangular de $1,4 \times 1 \mathrm{~m}$ formada por losas de pequeño y mediano tamaño. Muy próximo a esta estructura se localizó un pavimento de arcilla endurecida. Esta estructura se asociaba con cerámica a mano pintada postcocción en rojo y amarillo, un gran número de otras bruñidas y toscas, incisas e impresas y algún fragmento de los tipos Carambolo, retícula bruñida y grafitada (Fig. 3B). Las fechas de $\mathrm{C} 14$ obtenidas en este nivel son $2760 \pm 40$ BP; $2550 \pm 40$ BP; $2500 \pm 40 B P ; 2470 \pm 40$ BP.

\subsection{Estructuras de habitación (Cata U18)}

La cata se abrió en una zona de la ladera con una gran pendiente, sometida a fuerte erosión. Una vez levantadas las grandes piedras superficiales que habían servido como muros de bancales, apareció un hogar, muy próximo al descrito en U15, aunque a una cota algo superior. Se ha excavado solo la mitad, para poder conservarlo y conocer su estructura y potencia. Su forma es de placa circular ligeramente irregular (entre 1,30 y
1,40 m de diámetro), delimitada por piedras de pequeño tamaño y constituida por una capa de cenizas endurecida de $5 \mathrm{~cm}$ de potencia, asentada sobre el mismo tipo de piedras mezcladas con trozos de cerámicas y adobes. Tiene $17 \mathrm{~cm}$ de potencia. El escaso material arqueológico asociado al hogar se compone de cerámica lisa a mano y restos de fauna.

Muy cerca del hogar se encontró un poste de $30 \mathrm{~cm}$ de diámetro y $10 \mathrm{~cm}$ de potencia, fechado por $\mathrm{C} 14$ en $2600 \pm 40 \mathrm{BP}$. Es el único testimonio de la estructura de habitación del hogar. Ambos elementos se hallaron en un nivel de arcillas rojizas únicamente con cerámicas a mano.

En esta cata localizamos dos cabañas, ambas de gran interés porque no habían sido alteradas por ocupaciones posteriores (Fig. 5). Una de ellas tiene planta circular, mide 1,6 m de diámetro. Está delimitada por pequeñas piedras hincadas y tiene un suelo de tierra apisonada de $5 \mathrm{~cm}$ de potencia. Un poco desplazado del centro de la cabaña hacia el Este, hay un hoyo de un poste que sostendría la techumbre de $17 \mathrm{~cm}$ de profundidad, $40 \mathrm{~cm}$ de diámetro y rodeado por pequeñas piedras. Predominaba la cerámica lisa a mano con algunos fragmentos con decoración impresa en el borde. El pequeño tamaño de la cabaña nos sugiere más que una vivienda propiamente dicha, un anexo a otra estructura.

Fuera de la cabaña, hacia el Oeste, se encontró parte de un hogar o pavimento formado por

Trab. Prehist., 74, N. ${ }^{\circ}$ 1, enero-junio 2017, pp. 108-126, ISSN: 0082-5638

doi: $10.3989 /$ tp. 2017.12186 


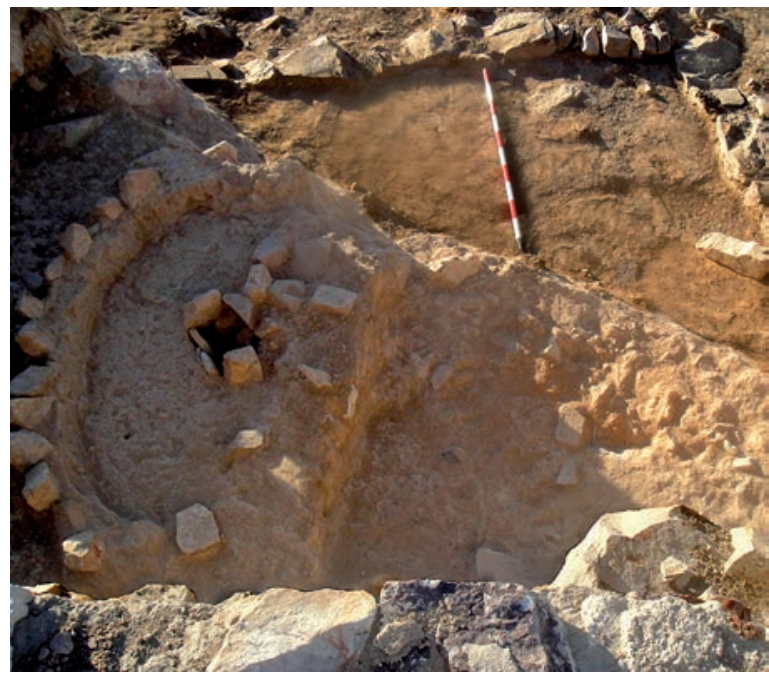

Fig. 5. Cabañas circular y rectangular de la Cata 18 del sector III de Alarcos.

barro endurecido y quemado de $2 \mathrm{~cm}$ de grosor, una capa de cantos y trozos de cerámica a mano y una base de arcilla rojiza. Su potencia total es de $13 \mathrm{~cm}$. No se han podido documentar ni su forma, ni dimensión.

Al suroeste de la cabaña circular y a una cota claramente inferior se localizó una habitación de planta rectangular, de la que se excavaron sus muros occidental y meridional, ya que el resto estaba bajo la cabaña circular. Los muros con $40 \mathrm{~cm}$ de ancho y $37 \mathrm{~cm}$ de altura conservada están formados por tres hiladas de piedras.

Las de la hilada superior eran más pequeñas y menos uniformes que las inferiores de tamaño mediano, trabajadas y bien ajustadas entre sí.

En el interior de este recinto apareció un suelo de arcilla endurecida y restos cerámicos, entre los que destaca un recipiente de gran tamaño al que solo falta el fondo. Está hecho a mano y es de pasta y superficies marrones. La exterior se ha bruñido. Tiene un gran cuello acampanado acabado en un borde redondeado vuelto y el cuerpo es globular. La decoración cubre prácticamente toda su superficie exterior con líneas incisas muy profundas, formando ángulos encadenados (Fig. 6).

También se conserva el pequeño cuello con borde saliente de un plato de retícula bruñida hecho a mano, de pasta gris oscura. Unos triángulos decoran la superficie exterior y una banda ancha que enmarca un zig-zag la interior (Fig. 7: 1). Las

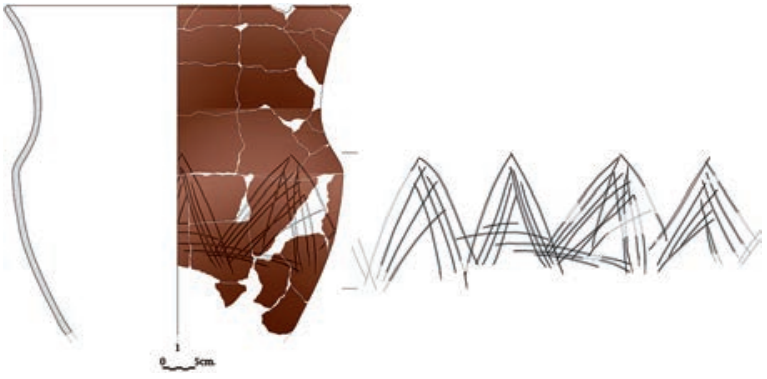

Fig. 6. Recipiente inciso hallado en la cabaña rectangular de la Cata U18, sector III de Alarcos. En color en la versión electrónica.

cerámicas pintadas bícromas y monocromas, las bruñidas, impresas y toscas sin decoración completan el conjunto (Fig. 3C). En el interior de esta vivienda se recogieron carbones de madera de matorrales y encina, utilizada para la cubierta y/o como combustible en el hogar. Se fechó una muestra por radiocarbono: $2590 \pm 40 \mathrm{BP}$.

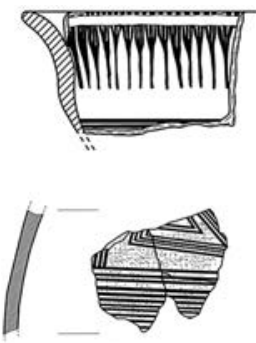

2

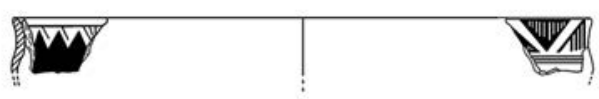

5
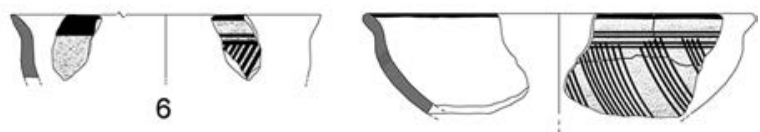

7

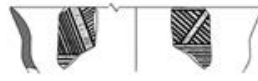

8
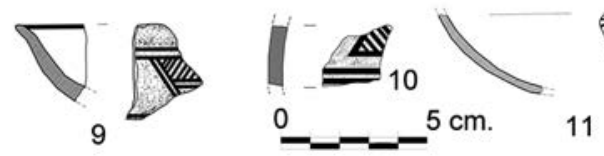

Fig. 7. Cerámicas decoradas del sector III de Alarcos: 1 - 4 retícula bruñida; 5-11 tipo Carambolo. 


\section{ESTUDIO DE LAS CERÁMICAS}

\subsection{Cerámica de retícula bruñida}

En Alarcos se conocía un ejemplar de este tipo cerámico. Apareció descontextualizado en la zona de la Alcazaba (García Huerta y Rodríguez 2000: 52). Hasta el momento en este sector de Alarcos solo se han documentado pequeños fragmentos que suelen pertenecer a recipientes abiertos como platos, cuencos o cazuelas, cuyas superficies interna y externa son aptas para la decoración sobre todo cerca del borde. Son de pequeñas dimensiones y paredes finas. Su fragilidad explica que aparezcan en fragmentos de reducido tamaño. Algún perfil está suavemente carenado. Los motivos decorativos son básicamente geométricos: líneas paralelas verticales, horizontales u oblicuas que configuran bandas o triángulos (Fig. 7: 1-4). Las pastas suelen estar bien tratadas y, tras el análisis de algunas, hemos conocido que su temperatura de cocción se sitúa en torno a los $750{ }^{\circ} \mathrm{C}$ y que contienen olivino. Este elemento es característico de zonas volcánicas, como el entorno de Alarcos, pero significativamente, salvo en las cerámicas de tipo Carambolo, falta en los más de 70 fragmentos de otras cerámicas de este período y de época ibérica analizados.

La cerámica de retícula bruñida, con acabados y motivos decorativos muy cuidados, suele aparecer asociada a la de tipo Carambolo. Ambas son características del Bronce Final en el área occidental de Andalucía y, como señala Escacena (2010: 116), "en la historiografía sobre Tartessos constituyen de alguna forma los más antiguos elementos usados por la investigación como 'fósiles guía' arqueológicos de esta fase". La presencia de elementos cerámicos como éstos en áreas distantes al núcleo tartésico es, pues, una firme evidencia de que existen relaciones entre las comunidades indígenas del interior y las dinámicas sociedades de la Baja Andalucía, que cristalizarán en el intercambio de materiales e ideas. También se han documentado recipientes cerámicos con retícula bruñida en yacimientos relativamente próximos a Alarcos, como La Bienvenida, donde se identificó olivino, como en Alarcos, en la composición mineralógica de las pastas de uno de ellos (Zarzalejos et al. 2004: 166).

\subsection{Cerámicas pintadas}

La cerámica a mano con decoración pintada se documenta en ámbitos culturales de la península ibérica como el tartésico y el de los Campos de Urnas desde el I milenio a.C. Se ha propuesto distintas teorías para explicar su origen, difusión y cronología, agrupándose en tipos y denominaciones diferentes que responden a la gran variedad de formas, motivos y colores empleados, así como a su contexto y área de dispersión (Werner 1990). En un artículo anterior (García Huerta y Fernández Rodríguez 2000) clasificamos las cerámicas pintadas en tres tipos: Carambolo, bicroma y monocroma. Sin embargo, al aumentar el número de piezas, advertimos que las últimas solo diferían en el número de colores: la técnica decorativa, los motivos, la pasta y las formas eran similares. Ello nos llevó a reducir las variantes a Carambolo y cerámicas pintadas.

\subsubsection{Cerámicas tipo Carambolo}

Este tipo decorativo se aplica sobre recipientes de pequeño y medio tamaño aunque de paredes algo más gruesas que las de retícula bruñida. Es un modelo de vajilla delicado, de uso selecto. $\mathrm{Su}$ relativa fragilidad explica su aparición en pequeños fragmentos, aunque la decoración se conserva bastante bien por la calidad de su fabricación $\mathrm{y}$, en especial, de su decoración aplicada. Las pastas están bien depuradas, con temperaturas de cocción entre $750{ }^{\circ} \mathrm{C}-850{ }^{\circ} \mathrm{C}$ y, según el análisis mineralógico ${ }^{1}$ realizado sobre dos fragmentos, la pasta contiene olivino. Los recipientes suelen presentar formas abiertas como cazuelas, cuencos, platos o vasos, en algún caso con suaves carenas o suaves perfiles en S. La decoración aparece en ambas superficies. Es básicamente geométrica, predominando las líneas paralelas

\footnotetext{
${ }^{1}$ A cargo de David Guirao Polo. Anexo I. Análisis mineralógico de cerámicas del Bronce Final y I Edad del Hierro del yacimiento de Alarcos (Ciudad Real). Informe inédito en el marco del proyecto "Investigaciones Arqueológicas en la necrópolis de Alarcos y el Sector II del yacimiento de Alarcos (Ciudad Real). Tipo: DGC/SPA SBPLY/14180601/000023" llevado a cabo en 2014. Financia la Consejería de Educación y Cultura de la Junta de Comunidades de Castilla-La Mancha.
} 
formando retículas, triángulos, rombos y denticulados (Fig. 7: 5-11). Como es un tipo cerámico muy significativo, sigue siendo reconocible a pesar del pequeño tamaño de los fragmentos $\mathrm{y}$, sobre todo en niveles bien contextualizados, resulta muy interesante.

El debate en torno a su filiación y marco cronológico ha dado lugar a propuestas que sitúan su origen tanto en el siglo IX a.C., o incluso antes (Werner 1990: 104), como en torno al siglo VII a.C. (Aubet 1982: 385). Escacena (2010: 121), tras analizar recientes excavaciones y revisar antiguos trabajos arqueológicos, lo fija entre finales del siglo IX - comienzos del VIII a.C., es decir, a partir de los momentos más antiguos de presencia fenicia. Las fechas radiocarbónicas que hemos obtenido parecen sugerir que, al menos en el siglo VIII a.C., ya estaban presentes en áreas del interior como la Meseta meridional y que su producción, o al menos su uso, pudo mantenerse hasta comienzos del siglo VII a.C.

Los principales motivos decorativos de este tipo de recipientes se enmarcan en una tendencia generalizada por toda la cuenca mediterránea, a partir del siglo $\mathrm{X}$ a.C., caracterizada por un patente geometrismo (Ruiz Mata 1989: 238; Casado 2003: 288), evidente también en tipos cerámicos como los de retícula bruñida o con decoración incisa. Este geometrismo se da en otros soportes como los huevos de avestruz, que posiblemente también contribuyeron a la difusión del fenómeno.

La cuidada elaboración requerida para lograr este tipo de cerámica con un acabado de innegable calidad es la prueba evidente de que era una producción selecta y reducida, que no estaba pensada ni para consumo general, ni para uso cotidiano. En algunos asentamientos del ámbito tartésico está asociada a funciones rituales integrada en contextos religiosos y/o funerarios (Ruiz Mata 2014: 10). Eso no quiere decir que necesariamente se produjese con ese fin, si no que su calidad la hacía merecedora de convertirse en vajilla ritual o de tener un uso selecto doméstico, quizás en sectores de la sociedad con un nivel de vida acomodado. En principio, los contextos de aparición de estas cerámicas en Alarcos apuntan a lugares de hábitat, donde serían especialmente valoradas. Ello explicaría su pervivencia varias generaciones después de haber sido elaboradas.

\subsubsection{Cerámicas pintadas monocromas y bicromas}

La cerámica pintada hallada en Alarcos tiene las pastas de color gris oscuro o negro y cocción reductora a una temperatura entre $700{ }^{\circ} \mathrm{C}$ y $800{ }^{\circ} \mathrm{C}$. La composición mineralógica, así como la proporción de los minerales presentan mucha similitud con otros tipos cerámicos presentes en Alarcos a lo largo del período ibérico ${ }^{2}$, por lo que pensamos que fueron elaboradas en el yacimiento. La pintura suele aplicarse postcocción sobre las superficies bruñidas, lo que dificulta su conservación y en ocasiones determinar el motivo. Los temas aparecen en la superficie exterior y/o interior según la forma del recipiente. Siempre se utilizan el rojo y el amarillo, solos o combinados (Fig. 8: $4-5,7-8,10,12)$. En las monocromas prevalece el color rojo (Fig. 8: 1-2, 6, 9, 11), aunque también las hay en amarillo (Fig. 8: 3). Los motivos, todos geométricos, van desde simples bandas o líneas horizontales al exterior o interior de los labios, a bandas o líneas horizontales, onduladas, oblicuas, verticales paralelas, a veces formando triángulos; círculos rellenos o puntos combinados con bandas y líneas. Es excepcional un friso complejo, como el del recipiente asociado al hogar 1 (Fig. 4).

Resulta difícil identificar sus formas dado el pequeño tamaño de los fragmentos recuperados. Todas corresponden a recipientes de reducida dimensión. Documentamos cuencos con borde vuelto bien de forma esférica con o sin un pequeño cuello (Fig. 8: 9-10), bien semiesférica (Fig. 8: 2-3); vasos o cuencos con carena más o menos alta y cuello acabado en un borde vuelto. Algunos presentan un mamelón perforado y otros decoración al interior (Fig. 8: 4-6, 8). Hay platos con decoración interior y, a veces, exterior (Fig. 8: 11) y copas o cuencos de pie alto (Fig. 8: 12). Estas formas son habituales en otras áreas y en otros tipos cerámicos, excepto las copas que no se han encontrado con este tipo de decoración en ningún yacimiento próximo.

Las cerámicas pintadas monocromas en rojo o amarillo y bicromas, en rojo y amarillo o blanco, aparecen en Andalucía, Murcia, Extremadura, la Meseta o el valle del Ebro en contextos del Bronce Final y Hierro I. Se ha escrito mucho sobre su

\footnotetext{
2 Véase n. 1.
}

Trab. Prehist., 74, N. ${ }^{\circ}$ 1, enero-junio 2017, pp. 108-126, ISSN: 0082-5638 doi: $10.3989 /$ tp.2017.12186 


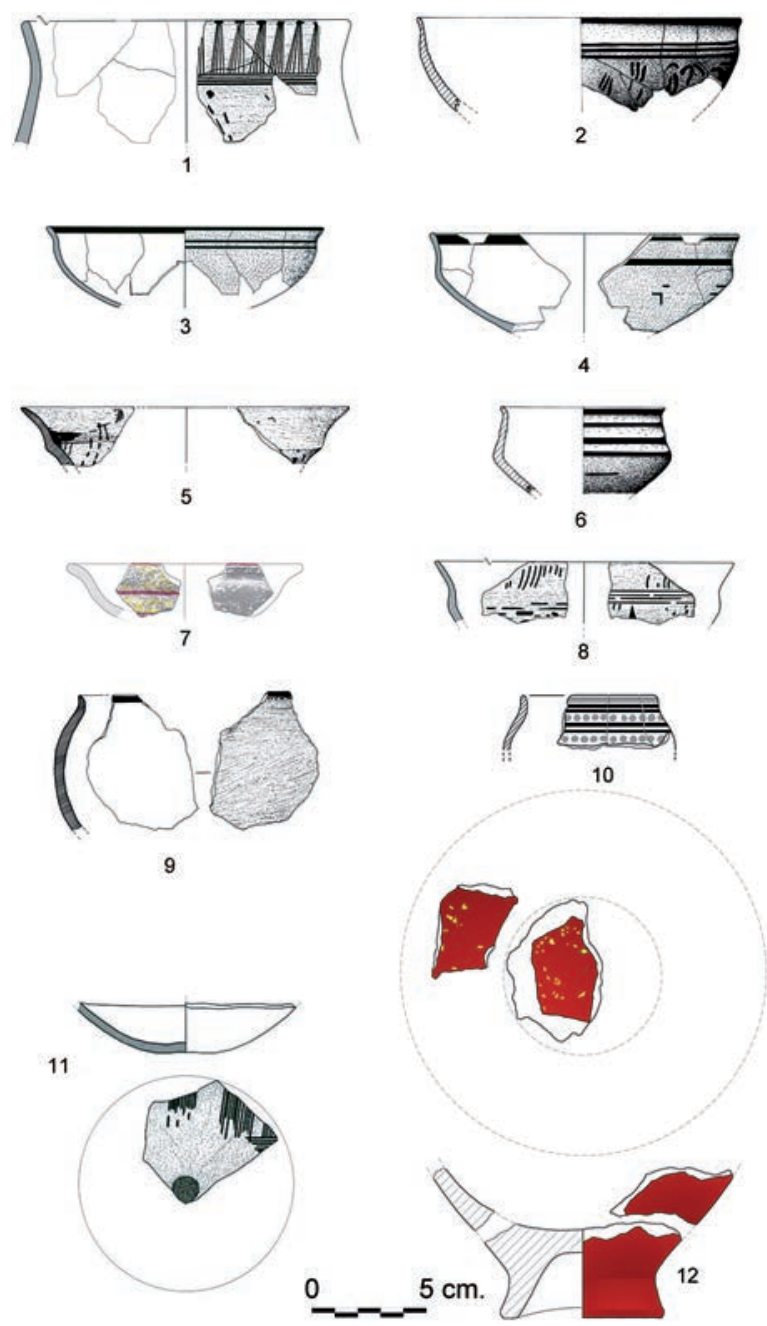

Fig. 8. Cerámicas pintadas postcocción del sector III de Alarcos. En color en la versión electrónica.

origen y modos de difusión (Pellicer 1989; Werner 1990), debido a la similitud en las formas y los motivos decorativos en diferentes regiones de la península ibérica. Ya hace años González Prats (1983: 119) explicaba la semejanza de los tipos decorativos por conexiones entre los diferentes grupos. En este sentido destacamos la similitud del recipiente de Alarcos (Fig. 4) con el vaso de Ogmico (Monreal de Ariza, Zaragoza) adscrito a Campos de Urnas y fechado en los siglos VIIVI a.C. (Rosa y García-Soto 1995: lám. 5). Sus motivos solo difieren de los de Alarcos en uno de los colores: blanco en lugar de amarillo y recuerdan a la cerámica tipo Carambolo representada en
Alarcos. Ambos son cuencos, aunque no exactamente iguales, de tamaño similar.

En poblados más próximos, como Cástulo (Jaén), aparecen cerámicas monocromas en rojo y alguna también en amarillo (Blázquez y Valiente 1981: 228), siendo estas menos frecuentes como sucede en Alarcos. Las bicromas, en rojo y amarillo, son muy escasas y dominan las pintadas en rojo y blanco, ausentes por el momento en Alarcos. Proceden de niveles fechados en los siglos VIII al VII a.C. (Blázquez y Valiente 1981: 235).

Todavía más cerca, en La Bienvenida hay cerámica pintada con decoración monocroma en rojo, en niveles del Bronce Final-Hierro I, que sus investigadores (Zarzalejos et al. 1994: 173-174) sitúan en los siglos VIII-VII a.C. En el siguiente período orientalizante, siglo VII y primera mitad del VI a.C., continúan las pintadas monocromas en rojo (tipo Guadalquivir II) y las bicromas, tipo Medellín, conviviendo ya con las primeras producciones a torno. En el poblado de Peñarroya, excavado por nosotros (García Huerta et al. 1999), solo se encontró un fragmento con decoración pintada en rojo, muy mal conservada, asociado a cerámicas a mano (incisas, impresas, grafitadas), y en un porcentaje muy bajo con las primeras a torno y algunas piezas de hierro. Fechamos el conjunto en el siglo VI a.C. Otro yacimiento, relativamente cercano, donde se repite la combinación de rojo y amarillo es el enterramiento de Casa del Carpio (Belvis de la Jara, Toledo). Entre el magnífico ajuar fechado en la primera mitad del siglo VII a.C. destacan numerosos cuencos completos, pintados en rojo y amarillo con una profusa y complicada decoración geométrica (Pereira 2007: 151-153).

En el propio Alarcos, en el lugar de aparición de seis enterramientos de incineración, la tumba 4 era un vaso a mano decorado con motivos radiales y líneas horizontales pintados en rojo. Fernández Rodríguez (2001: 275) ha fechado estas tumbas, entre las que hay cerámicas a mano con incrustaciones de bronce y a torno, entre los siglos VII y VI a.C.

\subsection{Cerámica a la almagra}

En Alarcos se conocían una treintena de fragmentos con esta decoración, procedentes del sector II y de la Alcazaba (García Huerta y Rodríguez 2000: 54). Las nuevas excavaciones en nuestro 
sector sólo han documentado unos fragmentos de galbos y dos bordes, uno procedente de un gran recipiente (Fig. 9: 1), en el nivel del hogar de la cata U11. Se conserva un cuello acampanado acabado en un borde vuelto, con un diámetro en la boca de $31,2 \mathrm{~cm}$. Está hecho a mano de pasta rojiza, con un engobe rojo muy fino, en ambas superficies. Tiene una perforación en el arranque del cuello. El tratamiento de la superficie es alisado.

En general el engobe rojo se aplica por inmersión o pincel antes de la cocción. En nuestro recipiente parece haberse recurrido a la inmersión ya que aparece en ambas superficies como una capa muy homogénea y muy fina pero solo alisada. En cambio los recipientes con esta decoración suelen estar bruñidos. Por ello habría que calificarla de pseudo-almagra o de mala calidad. La pequeñez del otro borde dificulta la identificación de la forma, pero presenta un engobe muy denso.

Las cerámicas almagras tienen una distribución geográfica, cultural y cronológica muy amplia. Limitándonos a las áreas más próximas a la nuestra, de nuevo, debemos referirnos al poblado de Cástulo, donde se combinan en los niveles de los siglos VIIVI a.C. con otras pintadas postcocción, grafitadas,
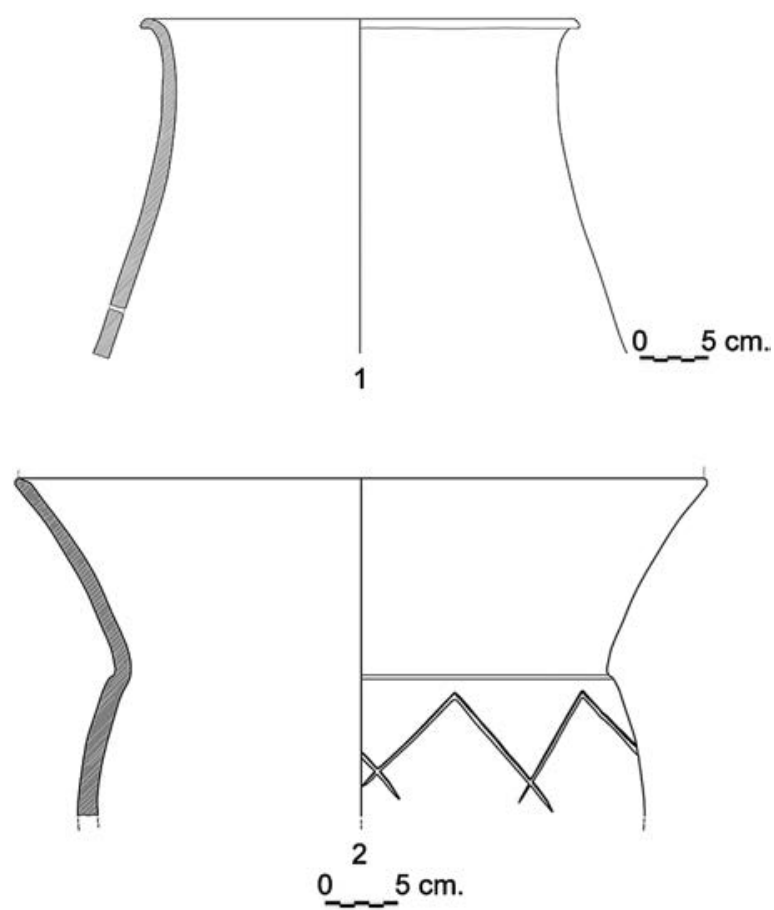

Fig. 9. Cerámicas decoradas del sector III de Alarcos: 1. a la almagra; 2. incisa. incisas y toscas sin decoración (Blázquez y Valiente 1981: 225-226). Aquí, a diferencia de Alarcos, los recipientes son muy numerosos y variados, incluso asociados a las técnica del grafito. En el poblados más cercano de La Bienvenida (Zarzalejos et al. 2012: 30-31) se fecha en los siglos VIII-VII a.C. y en el del cerro de las Cabezas, se halló un cuenco semiesférico de labio exvasado en los niveles del Bronce Final, similar a los encontrados en la Muela de Cástulo (Esteban et al. 2003: 21-22).

\subsection{Cerámicas grafitadas}

Es un tipo cerámico muy poco representado en Alarcos. De los 25 fragmentos recuperados solo tres proceden de contextos arqueológicos bien documentados, dos en el nivel del hogar de la cata U11 y otro en el hogar de la cata U15, el resto se ha recogido entre los tapiales de los niveles superficiales.

Las piezas están hechas a mano con paredes finas, salvo dos de mayor grosor. La cocción es reductora a una temperatura estimada en torno a los $750{ }^{\circ} \mathrm{C}$, obteniéndose una superficie gris homogénea. Las superficies están bruñidas con excepción de las correspondientes a los recipientes más gruesos. Los análisis para determinar cuándo se aplica el grafito revelan que se oxida y desaparece a $750{ }^{\circ} \mathrm{C}^{3}$. Como esa es la temperatura de cocción de la cerámica, parece razonable considerar que su aplicación debió ser posterior a la cocción. En la composición mineralógica de los fragmentos analizados falta la dolomita, un elemento muy habitual en las cerámicas de Alarcos. Su presencia no indica que se fabricaran allí, pero su ausencia sí resulta llamativa y podría indicar su procedencia de otro lugar. También se ha documentado un recipiente (Fig. 10: 1) con un doble tratamiento: superficie exterior grafitada y borde pintado al interior y exterior con una banda en rojo.

La escasez y el pequeño tamaño de las piezas solo han permitido identificar tres formas de mediano y pequeño tamaño, comunes a otros soportes decorativos: cuencos semiesféricos con o sin cuello, acabados en borde vuelto (Fig. 10: 1-2), y carenados (Fig. 10: 3, 5). Las cerámicas grafitadas presentan una amplia distribución geográfica y

\footnotetext{
3 Véase n. 1.
} 


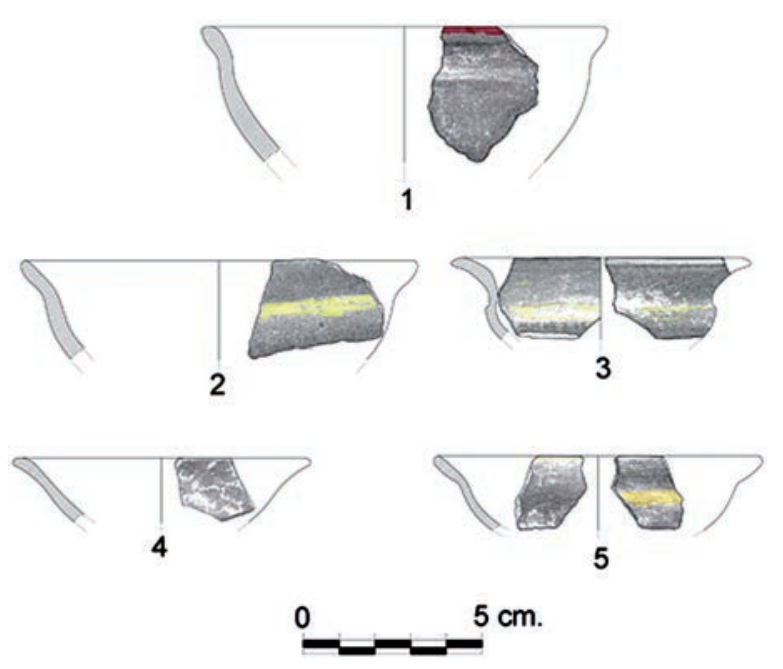

Fig. 10. Cerámicas grafitadas del sector III de Alarcos.

cronológica. Se concentran en el valle del Ebro y en la Meseta en niveles del Bronce Final-Hierro I (Barroso 2002: 130), aunque se extienden también hacia Levante y Andalucía. Como el grafito a veces es casi irreconocible pasó desapercibido en muchas excavaciones antiguas, siendo todavía insuficiente su conocimiento. En el poblado de Peñarroya aparece en un nivel fechado en el siglo VI a.C. (García Huerta et al. 1999: 249-250), junto con las primeras producciones a torno, y en el cerro de las Cabezas en un gran recipiente globular, asociado a cerámicas incisas, pintadas, bruñidas, almagras y sin decoración (Esteban et al. 2003: 1426), que sitúan en un momento avanzado del siglo VII a.C. El que sea la única cita hace pensar que la cerámica también escasea en este yacimiento.

En La Muela de Cástulo, las grafitadas sí son muy abundantes, a diferencia de lo que ocurre en Alarcos. Como las de Alarcos parecen de origen foráneo se compararon sus resultados analíticos con una de Cástulo (Rincón 1981: 237-238). Se dan algunas coincidencias pero la calcita es exclusiva de las de Alarcos, lo que indica que han sido elaboradas con diferentes componentes.

\subsection{Cerámicas incisas}

El número de cerámicas incisas documentadas en este sector de Alarcos ha aumentado con respecto a nuestro anterior estudio (García
Huerta y Fernández Rodríguez 2000). Hasta hemos podido identificar alguna forma completa, como el recipiente con cuerpo globular y cuello acampanado de la cabaña rectangular, tipo bastante representado en el yacimiento (Fig. 6). Por lo general, la incisión aparece sobre recipientes de mediano y gran tamaño, normalmente en su mitad superior. Los ángulos encadenados son uno de los motivos más habituales. Varía la modalidad de incisión (somera o más profunda), probablemente según el elemento punzante utilizado para su ejecución.

Las cerámicas con decoración incisa se conocen en contextos culturales muy diversos y desde cronologías muy antiguas por la sencillez de su elaboración. No obstante ciertas formas y motivos pueden adscribirse a un período cultural concreto. En el cerro de las Cabezas de Valdepeñas (Vélez y Pérez 1987: 174), Peñarroya (García Huerta et al. 1999: 236-237) o el cerro de las Nieves (Fernández Martínez et al. 1994: 119) aparecen en contextos fechados desde el siglo VIII al VI a.C. Las dataciones de $\mathrm{C} 14$ procedentes de la cabaña circular de Alarcos, donde precisamente se halló el recipiente mejor conservado de este tipo, van de finales del siglo IX hasta inicios del siglo VII a.C., coincidiendo con las obtenidas en otros asentamientos adscribibles a esta misma etapa en nuestro ámbito de estudio.

Las cerámicas a mano con decoración incisa son frecuentes en el horizonte cronológico del Bronce Final-Hierro I en diversas áreas de la península ibérica. Esta decoración se aplica sobre cuencos y cazuelas con perfiles acampanados o carenados, cuyos acabados suelen llevar tratamientos que van de los simples alisados a los bruñidos más cuidados. Los motivos suelen ser geométricos: triángulos, líneas quebradas, líneas paralelas verticales, horizontales u oblicuas y líneas onduladas.

$\mathrm{Su}$ sencillez y habitual presencia en etapas precedentes apuntan a una producción cerámica indígena que convive con tipos procedentes o inspirados en influencias mediterráneas. Según Escacena y otros (1998: 17) este tipo de cerámica "constituiría, junto a los vasos pintados de tipo Carambolo y a los decorados con motivos bruñidos, una expresión más del estilo geométrico que, como a otras culturas mediterráneas, afectó al mundo tartésico inmediatamente antes del fenómeno orientalizante". 
Cada vez hay más yacimientos del curso medio del Guadiana (Jiménez y Guerra 2012; Vilaça et al. 2012) y de la Meseta sur donde se documentan cerámicas incisas en contextos del Bronce Final-Hierro I. El yacimiento de Alovera en Guadalajara aporta las cronologías más antiguas en el siglo X a.C. (Espinosa y Crespo 1988: 251), aunque la mayoría de los autores consideran el siglo VII a.C. (Pereira 1994) o entre el siglo VIII y principios del VII a.C. (Zarzalejos et al. 2012: 31) como fechas más probable para las incisas en la Meseta meridional. Al basarse muchas de estas propuestas en materiales procedentes de prospecciones entendemos que nuestra aportación, fundamentada en fechas obtenidas en materiales bien contextualizados, será muy útil en futuros estudios cronológicos.

\subsection{Cerámicas impresas}

Este tipo cerámico es muy frecuente en las dos cabañas estudiadas en Alarcos. Suele aparecer en recipientes de almacenaje de superficies toscas o alisadas toscas de pastas de color oscuro o rojizo. La decoración consiste en digitaciones o ungulaciones en el borde (Fig. 11: 7-9) y en la pared exterior, a veces sobre cordón. Hay numerosos fragmentos pero ningún recipiente completo y resulta difícil identificar las formas. Aparecen cuellos acampanados y bordes vueltos de recipientes posiblemente ovoides o globulares.

Las cerámicas impresas son tan abundantes en diferentes contextos culturales que solo su asociación a otros tipos decorativos permite su adscripción concreta. Están en todos los yacimientos próximos a Alarcos con un horizonte preibérico: La Bienvenida (Zarzalejos et al. 1994:172), el cerro de las Cabezas (Esteban et al. 2003: 18) y

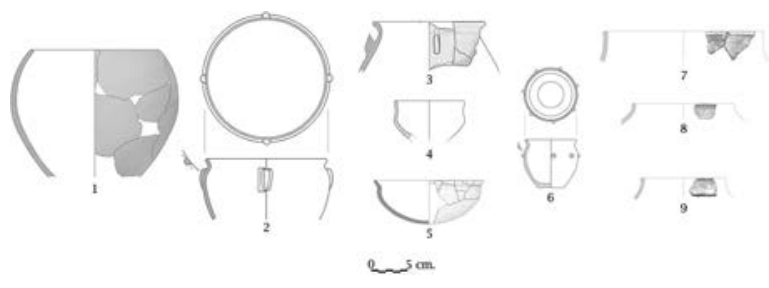

Fig. 11. Cerámicas del sector III de Alarcos: 1-6 alisadas toscas; 7-9 impresas.
Peñarroya (García Huerta et al. 1999: 236). En Alarcos están fechadas por C14 a partir del siglo IX a.C.

\subsection{Cerámicas sin decoración}

\subsubsection{Cerámicas con superficies bruñidas}

Se trata de una cerámica de gran calidad, con pastas en general finas, bien decantadas y superficies brillantes, calificadas por convención como bruñidas, ante la dificultad de distinguir la técnica empleada. Las superficies son negras o gris oscuro, aunque hay algunas de color beige-anaranjado. El tipo de recipiente determina el grosor de las paredes (2 a $4 \mathrm{~mm}$ ). Su gran abundancia, especialmente en la Cata U18, en el nivel de las cabañas y el hogar, ha permitido identificar desde recipientes de pequeño tamaño muy finos, de gran calidad y cuidada elaboración, a recipientes de tamaño medio y grande. Hay vasos con la carena más o menos alta y cuerpo de tendencia semiesférica y borde vuelto, con cuello más o menos desarrollado (Fig. 12: 1-2, 4); vasos de perfil en "S" (Fig. 12: 5); vasos de gran tamaño con cuello acampanado y cuerpo posiblemente ovoide o globular (Fig. 6); cuencos de formas semiesféricas (Fig. 12: 3) y vasos de tendencia globular con cuello (Fig. 12: 6). Esta cerámica se
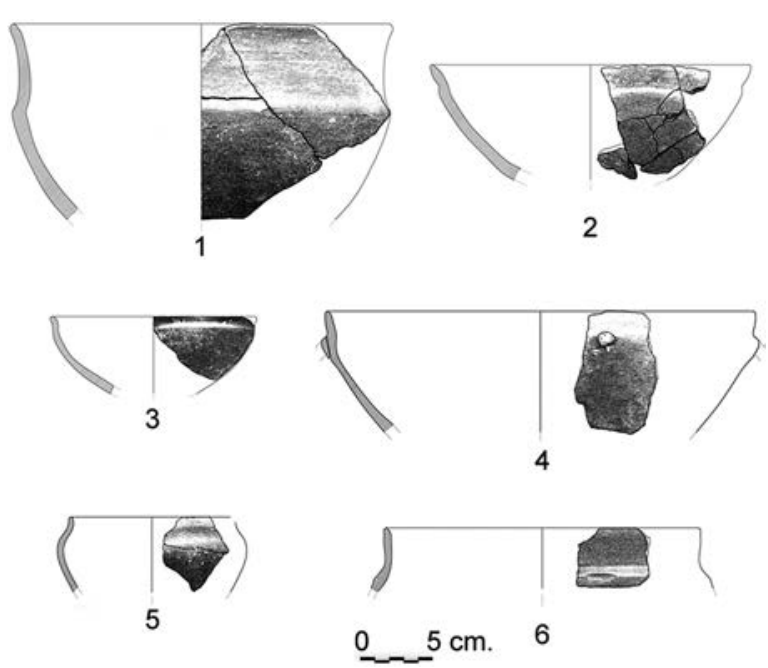

Fig. 12. Cerámicas bruñidas, sector III de Alarcos. 
halla en contextos del Bronce Final y de inicios del Hierro en casi todas las zonas. Las piezas de Alarcos son muy similares a las procedentes de la fase I de la Muela de Cástulo, fechada en el siglo VIII a.C. (Blázquez y Valiente 1981: 217). En La Bienvenida (Zarzalejos et al. 2012: 30) y el cerro de las Cabezas (Esteban et al. 2003: 20-21) se asocian a los tipos cerámicos pintados, incisos, almagras y en Peñarroya, conviven con las primeras cerámicas a torno, en los inicios de formación del mundo ibérico (García Huerta et al. 1999). En Alarcos abundan en las cabañas fechadas a partir del siglo IX a.C.

\subsubsection{Cerámicas con superficies alisadas o toscas}

Los fragmentos con superficie sin tratamiento o con un alisado tosco son numerosos al proceder de recipientes de tamaño medio o grande. En general las pastas son toscas con desgrasantes minerales de cuarzo, gruesos o semigruesos. Suelen ser grises oscuras y negruzcas, ya que dominan las cocciones reductoras, sin excluir algunas oxidantes y otras alternantes. Cuando las superficies no se quemaron al preparar alimentos tienen el mismo color que las pastas. La factura y el tratamiento varían. Las superficies oscilan entre un simple alisado a mano en las muy toscas y un alisado con mayor cuidado.

Destacan las formas para almacenamiento de gran tamaño, algunas con perforaciones para colgar y las de tamaño medio para la cocción. A veces presentan mamelones, perforados o no. Hemos reconstruido un número mínimo de 60 formas: recipientes ovoides con bordes entrantes sin cuello (Fig. 11: 1) o con cuello diferenciado y borde vuelto (Fig. 11: 2-3, 6); recipientes ovoides o esféricos con cuello cilíndrico o acampanado; cazuelas carenadas de tamaño medio (Fig. 11:4) y ollas de perfil en "S" con algún mamelón vertical (Fig. 11:6).

Estas cerámicas, ampliamente representadas en todos los yacimientos de este ámbito cultural, aportan poca información cronológica por sí mismas. En Alarcos se documentan desde el siglo IX a.C. y perviven hasta la etapa ibérica, conviviendo durante cierto tiempo con las cerámicas a torno (Tab. 1).

\subsection{Análisis mineralógico de las cerámicas ${ }^{4}$}

El estudio de la cerámica se completa con el análisis mineralógico de 6 fragmentos de diferente tipología, que ha permitido determinar algunos aspectos sobre su proceso de elaboración, así como de la procedencia de las inclusiones. Las muestras han sido analizadas a partir de microscopía óptica (MO), difracción de rayos X (DRX) y análisis colorimétrico. Las reducidas dimensiones de los fragmentos analizados no han permitido su estudio químico.

La figura 13 resume las características de los fragmentos estudiados, así como las imágenes captadas por MO de la superficie y del corte fresco, las cuales muestran los elementos pictóricos empleados y el tipo de inclusiones de las pastas cerámicas.

En la figura 14 se han expuesto 4 de los 6 difractogramas más representativos. Las muestras analizadas tienen, como minerales primarios, cuarzo (Q), filosilicatos (I-M), plagioclasas (Plg, excepto la muestra grafitada) y feldespatos potásicos $(\mathrm{Kfs})$. Las cerámicas son calcáreas salvo las dos de tipo Carambolo. Esta ausencia de calcita es un indicio de un proceso de producción diferenciado y probablemente también de un origen distinto. No se han detectado en ninguna de las muestras estudiadas minerales de cocción, que implican transformaciones originadas a partir de los 800-850 ${ }^{\circ} \mathrm{C}$, de lo que se deduce que la temperatura estimada para todas ellas se encuentra en el rango de los 700 y $800{ }^{\circ} \mathrm{C}$. Las muestras Carambolo I y II se sitúan en la parte más elevada de este rango.

$\mathrm{Al}$ analizar las particularidades de cada una de las muestras, se observa que las de tipo Carambolo y la de retícula bruñida se individualizan por presentar fases minerales asociadas al olivino (Ol), un mineral de origen volcánico que podría ser un indicativo de que tienen la misma procedencia. Una de las 4 regiones volcánicas de la península ibérica es, precisamente, el Campo de Calatrava, en el área de Alarcos. También se ha documentado olivino en la Sierra de Alacena (Huelva), dentro del ámbito de influencia territorial de Tartessos con el que se relacionan las cerámicas de tipo Carambolo y las de retícula bruñida.

\footnotetext{
${ }^{4}$ Véase $\mathrm{n} .1$.
}

Trab. Prehist., 74, N. ${ }^{\circ}$ 1, enero-junio 2017, pp. 108-126, ISSN: 0082-5638

doi: $10.3989 /$ tp. 2017.12186 


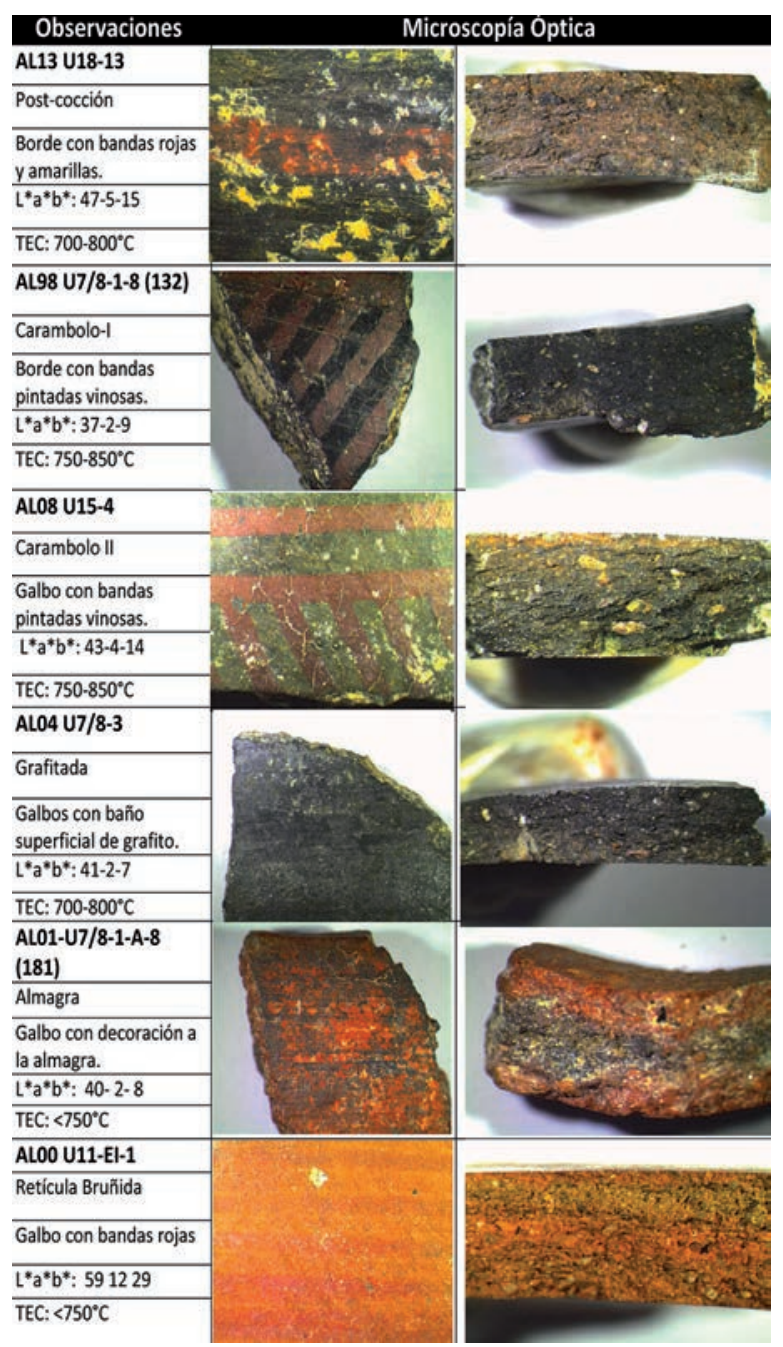

Fig. 13. Resumen de las características de los elementos pictóricos e inclusiones minerales de los 6 fragmentos cerámicos del sector III de Alarcos estudiados. Las observaciones se refieren al detalle de cada categoría por orden: Signatura de la muestra, Nombre de la muestra en el laboratorio, descripción decorativa, valores cromáticos en el sistema de medición internacional CIELAB, y TEC (temperatura estimada de cocción) expresado en grados. Imágenes captadas con el Microscopio Óptico del corte fresco (David Guirao. Anexo I. Análisis mineralógico de cerámicas del Bronce Final y I Edad del Hierro del yacimiento de Alarcos (Ciudad Real), inédito).

La dolomita (Dol) podría utilizarse como referencia para determinar el origen local de las muestras), aunque se trata de un mineral bastante común en materiales cerámicos. Aparece en las proximidades de Alarcos, así como en gran parte de las cerámicas ibéricas pintadas producidas allí. Las tres

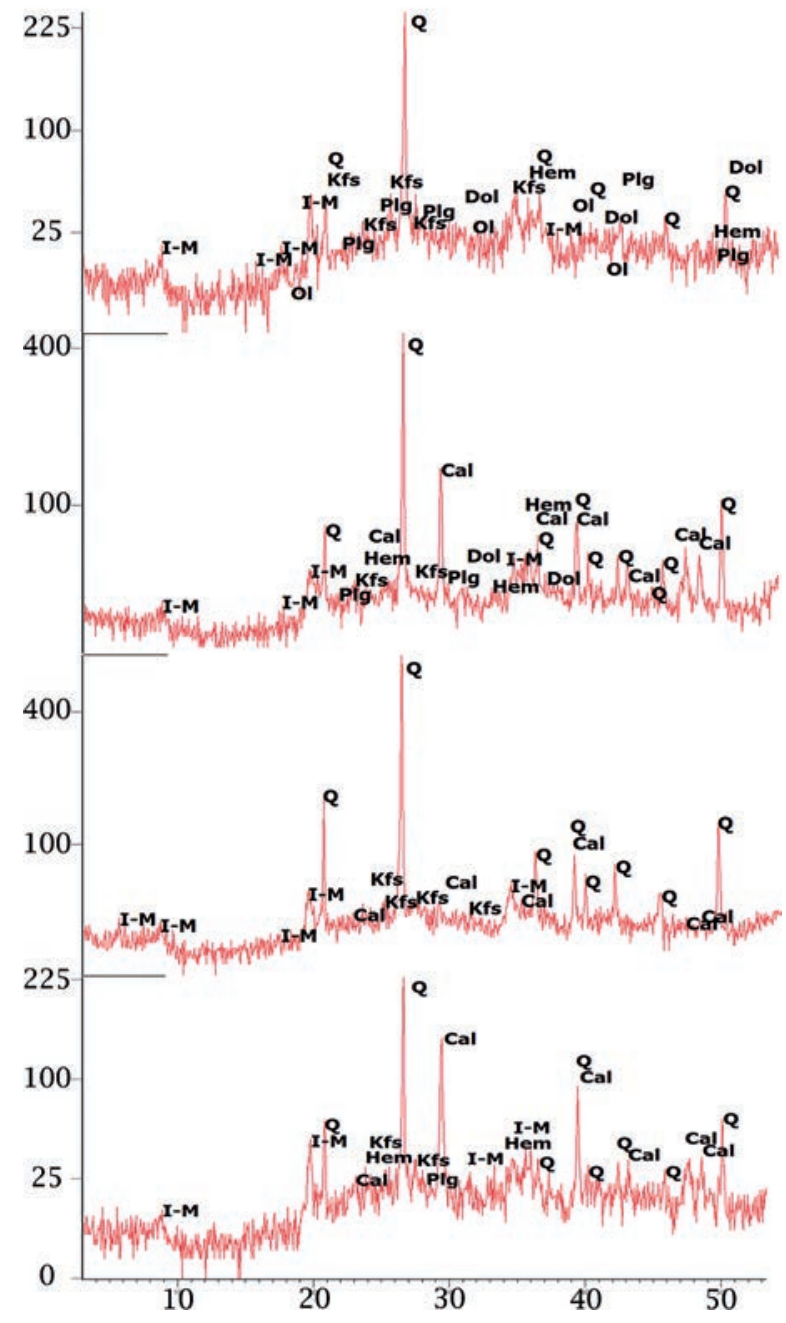

Fig. 14. Difractogramas por orden de las muestras $\mathrm{Ca}-$ rambolo II (AL08 U15-4), post-cocción (AL13 U18-13), grafitada (AL04 U7/8-3) y almagra (AL01-U7/8-1-A-8 (181). I-M (Grupo Illita-Montmorillonita); Q (cuarzo), Cal (calcita), Kfs (Feldespato potásico), Plg (plagioclasa), Hem (Hematites), Dol (Dolomita), OI (Olivino). (David Guirao. Anexo I. Análisis mineralógico de cerámicas del Bronce Final y I Edad del Hierro del yacimiento de Alarcos (Ciudad Real), inédito).

muestras con dolomita son la de tipo post-cocción y las de tipo Carambolo, donde su presencia podría contradecir el origen tartesio que a veces se le atribuye. Los hematites (óxidos de hierro) están asociados a la decoración pictórica en las cerámicas de tipo post-cocción, almagra y Carambolo.

Se han realizado varios ensayos para conocer el proceso decorativo de la cerámica grafitada. 
Los resultados permiten afirmar que los fragmentos estudiados han sido bañados de grafito una vez fueron cocidos, ya que su temperatura de cocción superó los $750{ }^{\circ} \mathrm{C}$ y el grafito, una variedad alotrópica del carbono, se descompone a los $700{ }^{\circ} \mathrm{C}$.

Las observaciones realizadas mediante $\mathrm{MO}$ reflejan la heterogeneidad de las muestras carentes de uniformidad en la textura, color y cocción de las pastas, así como en relación al tipo y número de inclusiones (cuarcitas, feldespatos, etc.).

\section{CONSIDERACIONES FINALES}

Queda patente la importancia que tuvo la ocupación del cerro de Alarcos en época preibérica, aunque todavía analizamos resultados provisionales que campañas arqueológicas posteriores deberán ratificar a partir de documentación recuperada en contextos arqueológicos bien definidos. Cada vez son más abundantes y variados los elementos y estructuras adscribibles a esa etapa, distribuidos además por la Alcazaba y los sectores II, III, IV y IV-E. La superficie global de dispersión de estos testimonios rondaría las 12 has, sugiriendo un hábitat de considerables dimensiones (García Huerta y Fernández Rodríguez 2000: 65).

Hasta hace poco más de una década el poblamiento preibérico era muy poco conocido en los territorios correspondientes a la provincia de Ciudad Real. Este período se caracterizaba mediante hallazgos casuales y, sobre todo, por el análisis y descripción de las estelas de guerrero. Resultaba llamativa la escasez de testimonios arqueológicos sobre esta etapa frente a los que se iban obteniendo para la etapa inmediatamente anterior del Bronce Pleno y la posterior ibérica. En los últimos años se han empezado a constatar niveles del Bronce Final-Hierro I, sobre todo en asentamientos que tendrán un especial protagonismo en el período ibérico como La Bienvenida, el cerro de las Cabezas y Alarcos. Todos ellos cuentan con proyectos de investigación desde hace más de dos décadas, lo cual explica que los hallazgos procedentes de estos asentamientos suelan caracterizar este período.

La considerable reducción del número de poblados en relación al periodo del Bronce Pleno ha llevado a algunos autores a plantear un notable descenso demográfico en este territorio, resultado de una masiva migración o una mayor mortandad (Fernández Rodríguez 2012: 43). Quizás la explicación esté más relacionada con la falta de información. Aún son pocos los asentamientos investigados con cierta profundidad, pero no es descartable que el aparente cambio de patrón de poblamiento, en realidad, reflejara la concentración de la población en menos asentamientos que, como el de Alarcos, alcanzarían notables dimensiones ya en época preibérica. Este nuevo modelo de poblamiento también parece percibirse en otras zonas del curso medio del Guadiana, como Badajoz (Enríquez 1990; Vilaça et al. 2012) y Alentejo (Berrocal-Rangel et al. 2012) y, según Ferrer y Bandera (2005: 566), caracteriza el área tartésica y sus regiones periféricas en el período orientalizante. Las razones concretas de este cambio son complejas, aunque necesariamente se vinculan con una nueva dinámica económica que precisaría una explotación más intensa de las fértiles vegas del Guadiana y sus afluentes (quizás relacionada con la "colonización agraria" defendida por Ferrer y Bandera 2005) y una disposición más estratégica respecto a las nuevas rutas comerciales que van a prefigurarse en este momento. En cualquier caso, recordemos que la identificación de los yacimientos del Bronce Final se basa en materiales arqueológicos como los presentados en este trabajo, muy significativos pero escasos, lo que hace muy difícil su reconocimiento en prospecciones superficiales. Se acompañan de cerámicas más abundantes y comunes, cuyas formas y decoraciones mantienen los tipos de tradiciones anteriores. Esta circunstancia podría estar "ocultando" algunos asentamientos de este período en las cartas arqueológicas, donde algunas de las referencias genéricas a yacimientos de la Edad del Bronce podrían corresponder al período preibérico.

Como ya hemos señalado, nuestro estudio se centra en el sector III del poblado de Alarcos. La información procede de un área reducida y muy condicionada por la presencia de importantes edificaciones de época ibérica y medieval. Sin embargo, las estructuras documentadas y los materiales recuperados reflejan un hábitat bastante dinámico, al menos desde finales del siglo IX a.C., según las fechas de C14 (Tab.1) obtenidas en las cabañas circular y rectangular y en los hogares de las Catas U7/8 y U15. Estos pobladores mantendrían contactos, directos o indirectos, sobre todo con el área del sudoeste peninsular, que

Trab. Prehist., 74, N. ${ }^{\circ}$ 1, enero-junio 2017, pp. 108-126, ISSN: 0082-5638

doi: $10.3989 /$ tp.2017.12186 
en esos momentos mostraba mayor dinamismo por unas influencias atlánticas y mediterráneas, que se harán especialmente intensas a partir del siglo VIII a.C.

Estos contactos se manifiestan en la llegada de elementos materiales de clara inspiración tartésica como las cerámicas de tipo Carambolo y de retícula bruñida. Su número es muy escaso, pero precisamente esa circunstancia refuerza su consideración como producciones foráneas y, en concreto, del ámbito tartésico. Se trataría de productos importados que formarían parte de lotes comerciales selectos que probablemente incluyeran materiales perecederos.

La colaboración interdisciplinar está aportando una interesante información complementaria para debatir con datos más objetivos la génesis y difusión de materiales arqueológicos. Estudios arqueométricos, como los realizados hace unos años sobre "un recipiente" con decoración de retícula bruñida de La Bienvenida, han identificado cristales de olivino entre los componentes de las pastas. Este mineral es propio de áreas volcánicas, lo que llevó a plantear que algunas de estas cerámicas, consideradas de influencia tartésica, pudieran ser producciones locales (Zarzalejos et al. 2012: 28). De este modo, frente a la idea tradicional a favor de exportaciones de productos acabados, se abriría la posibilidad de que los movimientos de ideas y modas explicaran mejor la presencia de elementos materiales fuera de sus zonas de origen. Recordemos como, para Escacena (2000: 117), el oficio de alfarero "pudo ser uno de tantos oficios ambulantes de la Prehistoria".

Los análisis mineralógicos en cerámicas de retícula bruñida de Alarcos confirman la presencia de olivino lo cual, en principio, podría ser interpretado como una corroboración de la hipótesis de la producción local del tipo, expresada por el equipo que trabaja en La Bienvenida. Sin embargo entendemos que este tipo de análisis exigen ampliar la perspectiva para poder evaluar sus posibles implicaciones y consecuencias. La identificación de olivino en la cerámica de retícula bruñida de Alarcos es muy significativa, pero su relevancia aumenta ya que, salvo en la cerámica tipo Carambolo, falta en las otras muestras analizadas de época ibérica y preibérica. La presencia de olivino es habitual en la zona volcánica de estudio por lo que lo realmente llamativo es su ausencia en las demás cerámicas, sobre todo en las más comunes.
Nos podríamos enfrentar a un complejo problema de interpretación si no hubiera olivino en áreas vinculadas con el mundo tartésico. Pero su presencia, apuntada en el entorno del yacimiento onubense de El Trastejón (Hurtado et al. 2011), nos obliga a replantear la génesis y difusión de este tipo tan significativo de material cerámico.

En La Bienvenida aparece el olivino en la composición de las pastas de algunas cerámicas de época ibérica, lo que no ocurre en Alarcos. Sin embargo, según los datos analíticos actuales, las cerámicas tipo retícula bruñida y Carambolo de Alarcos son de producción foránea. Para precisar su origen habrá que incidir en estudios arqueométricos planteados con una metodología común de resultados contrastables que permita alcanzar conclusiones más globales.

La composición de las cerámicas grafitadas, asimismo distinta de la del resto de las analizadas, parece indicar que tampoco se fabricaron en Alarcos. De nuevo, nos resulta difícil establecer su posible origen. El gran número de grafitadas y de otros tipos cerámicos como los presentes en Alarcos, recuperados en el cerro de la Muela de Cástulo, ha hecho pensar en una posible relación entre los poblados del alto Guadiana y Cástulo (Fernández Rodríguez 2012: 60). Faltan análisis con metodologías similares para establecer comparaciones que determinen si hubo o no contacto.

Las características de los recipientes recuperados desde, al menos, finales del siglo IX a.C. reflejan la existencia de un buen artesanado: amplio elenco de tipos y calidad de ejecución, incluso en los de clara factura endógena, con pastas bien trabajadas y buenos acabados superficiales como bruñidos. Estos alfareros dominan la técnica para dar servicio a una exigente demanda y producen cerámicas como las almagras $\mathrm{y}$, sobre todo, como el llamativo ejemplar pintado postcocción cuyas analíticas han demostrado su realización en este poblado del Alto Guadiana (Fig. 4).

El conjunto de evidencias indican que Alarcos es un hábitat bastante consolidado desde comienzos del I milenio a.C., como corroboran las fechas de $\mathrm{C} 14$ que, asimismo nos confirman que entre finales del II milenio y comienzos del I a.C. se produce un cambio en el patrón de poblamiento en este ámbito meseteño. La población abandona las motillas y castellones para concentrarse en nuevos emplazamientos, como Alarcos, cuya tradición cultural, claramente enraizada en la Edad 
del Bronce, es apreciable en algunos tipos cerámicos. Otros son respuestas locales a la influencia de las cerámicas de retícula bruñida o de tipo Carambolo, procedentes de otros territorios.

Además las estructuras de habitación refuerzan nuestra hipótesis de que nos encontramos ante un poblamiento bastante consolidado desde comienzos del I milenio a.C. La parcialidad de las excavaciones no ha impedido reconocer un modelo de cabañas circulares y otro de habitaciones rectangulares asociadas a hogares, que remiten a un asentamiento permanente y no esporádico como podrían sugerir estructuras más endebles. Este modelo de poblado está ampliamente representado en el sur peninsular. Allí, según Suárez y Márquez (2014), desde el Bronce Final aparecen poblados fortificados en altura con cabañas de piedra de plantas rectangulares y ovaladas, hechas con zócalos de piedra, que continuarán durante la transición del Bronce Final al Hierro I, si bien junto a estas tradiciones habitacionales se incorporaran nuevos elementos como las cabañas circulares y los edificios rectangulares complejos de tradición fenicia. Esta será la que acabe por consolidar el modelo de hábitat basado en construcciones rectangulares, un modelo, por otra parte, con antecedentes en tradiciones constructivas indígenas anteriores como se aprecia en asentamientos del Bronce Pleno como las motillas y los castillejos.

En definitiva, este repertorio reducido, pero variado y significativo por su calidad y valor estético de las cerámicas, documenta la llegada a la Meseta meridional de productos de prestigio, vinculados con flujos comerciales procedentes del Bajo Guadalquivir. Allí se asientan poblaciones con un notable dinamismo inducido por sus contactos con el mundo atlántico y mediterráneo. La evidencia arqueológica no parece justificar para este área del Alto Guadiana una expansión colonial tartésica como la que podría llegar hasta Sisapo-La Bienvenida (Almagro Gorbea (2010: 190-191). Se trata de una vajilla cuidada, pensada para un uso selecto que reproduce, probablemente, modas y costumbres también foráneas. Para que esta relación comercial fuese fluida era preciso que la población asentada en sitios como Alarcos hubiese alcanzado un nivel básico de consolidación urbana, una notable capacidad de producción primaria y artesanal y un cierto nivel organizativo. Las élites allí asentadas consumen productos de prestigio desde fechas anteriores al siglo VIII a.C., como corroboran los datos ya expuestos, que manifiestan como el notable protagonismo alcanzado por Alarcos en época ibérica se fundamenta en el importante nivel de desarrollo alcanzado en el período preibérico.

\section{AGRADECIMIENTOS}

Al dr. David Guirao Polo por la realización de los análisis de las cerámicas de Alarcos.

\section{BIBLIOGRAFÍA}

Almagro Gorbea, M. 2010: "La colonización tartésica: toponimia y arqueología". Paleohispánica 10: 187-199.

Aubet, E. 1982: "Un vaso a mano con decoración pintada de los Alcores de Carmona". Trabajos de Prehistoria 39: 385-388.

Barroso Bermejo, R. 2002: "Cuestiones sobre las cerámicas grafitadas del Bronce Final y I Edad del Hierro de la Península Ibérica". Trabajos de Prehistoria 59 (1): 127-142.

Berrocal, L.; Silva, A. y Prados, F. 2012: "El Castro de Ratinhos, un ejemplo de orientalización entre las jefaturas del Bronce Final del Suroeste". En J. Jiménez Ávila (ed.): Sidereum Ana II. El río Guadiana en el Bronce Final. Anejos de Archivo Español Arqueología LXII, CSIC. Mérida: 167-184.

Blázquez, J. M. y Valiente, J. 1981: Castulo III. Excavaciones Arqueológicas en España117, Ministerio de Cultura. Madrid.

Casado, M. J. 2003: "Reflexiones sobre la cerámica tipo Carambolo. ¿Un axioma de la arqueología protohistórica del suroeste andaluz”. SPAL 12: 283-298.

Enríquez, J. J. 1990: "Sobre algunos poblados del Bronce Final de la provincia de Badajoz". Norba 10: 41-57.

Escacena, J. L. 2000: La arqueología protohistórica del sur de la Península Ibérica. Síntesis. Madrid.

Escacena, J. L. 2010: "El Carambolo y la construcción de la arqueología tartésica". En M. ${ }^{a}$ L. de la Bandera y E. Ferrer (eds.): El Carambolo. 50 años de un tesoro. Universidad de Sevilla. Sevilla: 99-150.

Escacena, J. L.; Río, A. del; Luna, M. A. 1998: “Cerámica tartésica con decoración grabada. Nuevos testimonios". Anales de Arqueología Cordobesa 9: 9-23.

Espinosa, C. y Crespo, M. L. 1988: “Un yacimiento de la transición del Bronce al Hierro en Alovera (Guadalajara)". I Congreso de Historia de Castilla- 
La Mancha, III. (2) Pueblos y culturas prehistóricas y protohistóricas: 247-256. Ciudad Real.

Esteban, G.; Hevia, P.; Pérez Avilés, J. J. y Vélez, J. 2003: "La transición del Bronce Final a la Primera Edad del Hierro en el Cerro de las Cabezas (Valdepeñas, Ciudad Real)". Cuadernos de Estudios Manchegos 25-26: 11-42.

Fernández Martínez, V. M.; Hornero, E. y Pérez, J. A. 1994: "El poblado ibérico del cerro de las Nieves (Pedro Muñoz). Excavaciones 1984-1991". Arqueología en Ciudad Real. Patrimonio Histórico-Arqueología, Castilla-La Mancha 8. Toledo: 111-130.

Fernández Rodríguez, M. 2000: "El poblamiento ibérico en Alarcos". El Patrimonio Arqueológico en Ciudad Real al final del milenio: métodos de trabajo y actuaciones recientes. UNED. Valdepeñas: 123-136.

Fernández Rodríguez, M. 2001: “La necrópolis del Sector IV de Alarcos (Ciudad Real)". En R. García Huerta y F. J. Morales (ed.): Arqueología funeraria: las necrópolis de incineración. Universidad de Castilla-La Mancha. Cuenca: 259-284.

Fernández Rodríguez, M. 2012: “Apuntes sobre el Bronce Final en Alarcos". En J. Jiménez Ávila (ed.): Sidereum Ana II. El río Guadiana en el BronceFinal. Anejos de Archivo Español Arqueología LXII, CSIC. Mérida: 41-64.

Fernández Rodríguez y García Huerta, R. 1998: “El urbanismo del poblado ibérico de Alarcos (Ciudad Real)". En C. Aranegui (ed.): Actas del Congreso Internacional. Los Iberos Príncipes de Occidente: las estructuras de poder en la sociedad ibérica (Barcelona 1998). Saguntum. Papeles del Laboratorio de Arqueología de Valencia, Extra 1: 47-54.

Ferrer, E. y Bandera, M. L. de la 2005: "El orto de Tartessos: la colonización agraria durante el período orientalizante". En S. Celestino y J. J. Jiménez Ávila (eds.): El periodo orientalizante. Actas del III Simposio Internacional de Arqueología de Mérida: Protohistoria del Mediterráneo Occidental I, Anejos delArchivo Español de Arqueología XXXV, CSIC. Mérida: 565-574.

García Huerta, R.; Morales, F. J. y Ocaña, A. 1999: "El poblado de la Edad del Hierro de Peñarroya, Argamasilla de Alba, Ciudad Real”. En M. A. Valero (ed.): I Jornadas de Arqueología Ibérica en Castilla-La Mancha (Iniesta, Cuenca 1997): 221258. Toledo.

García Huerta, R. y Fernández Rodríguez, M. 2000: "La génesis del mundo ibérico en la submeseta sur: el tránsito del Bronce Final-I Edad del Hierro en Alarcos". Cuadernos de Prehistoria y Arqueología de la Universidad Autónoma de Madrid 26: 47-68.

García Huerta, R. y Morales Hervás, F. J. 2009: “Almacenamiento, tratamiento y conservación de alimentos en los pueblos ibéricos de la Meseta meridional". En R. García Huerta y D. Rodríguez (eds.): Sistemas de almacenamiento entre los pueblos prerromanos peninsulares. Universidad de Castilla-La Mancha. Cuenca:167-208.

González Prats, A. 1983: Estudio arqueológico del poblamiento antiguo de la Sierra de Crevillente (Alicante). Anejo I Lucentum, Universidad de Alicante. Alicante

Hurtado, V.; García San Juan, L. y Hunt, M. A. (ed.) 2011: El asentamiento de El Trastejón (Huelva). Investigaciones en el marco de los procesos sociales $y$ culturales de la Edad del Bronce en el Suroeste de la península ibérica. Junta de Andalucía. Consejería de Cultura. [Sevilla].

Jiménez Ávila, J. y Guerra Millán, S. 2012: “El Bronce Final en Medellín. Estudio preliminar del Corte SMRO”. En J. Jiménez Ávila (ed.): Sidereum Ana II. El río Guadiana en el Bronce Final. Anejos de Archivo Español Arqueología LXII, CSIC. Mérida: 65-110.

Morales Hervás, F. J. 2010: El poblamiento de época ibérica en la provincia de Ciudad Real. Universidad de Castilla-La Mancha. Cuenca.

Pellicer, M. 1989: "El Bronce reciente y los inicios del Hierro en Andalucía occidental". Tartessos. Arqueología Protohistórica del Bajo Guadalquivir. Ausa. Sabadell: 147-187.

Pereira Sieso, J. 1994: "La transición del Bronce Final al Hierro en la Meseta Sur”. En La Edad del Bronce en Castilla-La Mancha. Actas del Simposio, 1990. Diputación Provincial de Toledo. Toledo: 37-85.

Pereira Sieso, J. 2007: "El Bronce Final y los inicios de la Edad del Hierro". En J. Pereira (ed.): Prehistoria y Protohistoria de la Meseta Sur (Castilla-La Mancha). Almud. Ciudad Real: 127-158.

Pérez Avilés, J. J. y Vélez, J. 1996: "Estudio sobre la Protohistoria de Valdepeñas y su comarca". Cuadernos de Estudios Manchegos 22: 9-38.

Reimer, P. J.; Baillie, M. G. L.; Bard, E.; Bayliss, A.; Beck, J. W.; Bertrand, Ch. J. H.; Blackwell, P. G.; Buck; C. E.; Burr, G. S.; Cutler, K. B.; Damon, P. E.; Edwards, R. L.; Fairbanks, R. G.; Friedrich, M.; Guilderson, Th. P.; Hogg, A. G.; Hughen, K. A.; Kromer, B.; McCormac, G.; Manning, S.; Ramsey, Ch. B.; Reimer, R. W.; Remmele, S.; Southon, J. R.; Stuiver, M.; Talamo, S.; Taylor, F. W.; van der Plicht, J.; Weyhenmeyer, C. E. 2004: "INTCAL04 terrestrial radiocarbon age calibration, 0-26 CAL KYR BP”. Radiocarbon 46, 3: 1029-1058.

Rincón, J. M. 1981: "Estudio de la composición de los colorantes superficiales de dos cerámicas del poblado de la Muela de Cástulo (Linares, Jaén). Anexo I". En J. M. Blázquez y J. Valiente: Cástulo III. Excavaciones Arqueológicas en España 117, Ministerio de Cultura. Madrid: 237-242.

Rosa Municio, R. de la y García-Soto, E. 1995: “Cero Ógmico. Un yacimiento de campos de urnas en el alto Jalón". III Simposio sobre los celtíberos (Daroca 1995). Poblamiento celtibérico: 265-274. Zaragoza.

Trab. Prehist., 74, N. ${ }^{\circ}$ 1, enero-junio 2017, pp. 108-126, ISSN: 0082-5638 doi: $10.3989 /$ tp.2017.12186 
Ruiz Mata, D. 1989: "Huelva: un foco temprano de actividad metalúrgica durante el Bronce Final". Tartessos. Arqueología prehistórica del Bajo Guadalquivir. Ausa. Sabadell: 209-243.

Ruiz Mata, D. 2014: "La cerámica pintada geométrica tartésica". La pieza del mes. 27 de septiembre de 2014. Museo Arqueológico Municipal de Jerez, Asociación de Amigos del Museo. https:// amigosdelmuseo.files.wordpress.com/2014/09/pieza_sept-_la_ceramica_tartesica.pdf (consulta 171-2017)

Suárez Padilla, J. y Márquez Romero, J. E. 2014: “La problemática de los fondos de cabaña en el marco de la arquitectura protohistórica del Sur de la Península Ibérica". Menga 5: 199- 225.

Talma, A. S. y Vogel, J. C. 1993: “A simplified approach to calibrating C14 dates". Radiocarbon 35 (2): 317-322.

Vélez, J. y Pérez Avilés, J. J. 1987: “El yacimiento protohistórico del cerro de las Cabezas". Oretum III: $167-196$.

Vilaça, R.; Jiménez, J. y Galán, E. 2012: “El poblado de Los Concejiles (Lobón, Badajoz) en el contexto del Bronce Final del Guadiana Medio". En J. Jiménez Ávila (ed.): Sidereum Ana II. El río Guadiana en el Bronce Final. Anejos de Archivo Español Arqueología LXII, CSIC. Mérida: 125-166.
Werner, S. 1990: La cerámica pintada geométrica del Bronce Final y de la Primera Edad del Hierro. Ed. La Muralla. Madrid.

Zarzalejos, M.; Esteban, G. y Hevia, P. 2012: “El Bronce Final en el Alto Guadiana. Viejos y nuevos datos para una lectura histórica". Sidereum Ana II. El río Guadiana en el Bronce Final. Anejos de Archivo Español de Arqueología LXII, C.S.I.C. Mérida: 1540.

Zarzalejos, M.; Fernández Ochoa, C.; Hevia, P. 2004: "El proyecto Sisapo-La Bienvenida (Almodóvar del Campo, Ciudad Real). Investigaciones Arqueológicas en Castilla-La Mancha 1996-2002. Patrimonio Histórico Arqueología 18: 163-180.

Zarzalejos, M.; Fernández Ochoa, C.; Hevia, P. y Esteban, G. 1994: "Excavaciones en La Bienvenida (Ciudad Real). Hacia una definición preliminar del horizonte histórico- arqueológico de la Sisapo antigua". Arqueología en Ciudad Real. Patrimonio Histórico- Arqueología 8. Toledo: 167-194.

Zarzalejos, M. y López Precioso, F. J. 2005: “Apuntes para una caracterización de los procesos orientalizantes en la Meseta Sur". En S. Celestino y J. J. Jiménez Ávila (eds.): El periodo orientalizante. Actas del III Simposio Internacional de Arqueología de Mérida: Protohistoria del Mediterráneo Occidental I, Anejos del Archivo Español de Arqueología XXXV, CSIC. Mérida: 809-842. 